\title{
ON THE CHOICE OF SCHOOLS LOCATED OUTSIDE THE WALKABLE NEIGHBOURHOOD OF THE HOUSEHOLD
}

\author{
A. A. OSAGIEDE AND V. U. EKHOSUEHI \\ (Received 28, May 2009; Revision Accepted 4, November 2009)
}

\begin{abstract}
In this study, we consider a school choice problem and formulate it into a mathematical model, allowing it to be simplified and solved. The results obtained are useful for the household in making an objective choice of school for the child to be enrolled among several secondary schools located outside his walkable neighbourhood which best satisfies his budget constraint with emphasis on the most preferred travelling mode of a given type.
\end{abstract}

KEYWORDS: School choice modelling; Lagrangian function; Stone's utility function; Saturation point.

\section{INTRODUCTION}

Earlier studies on school choice modelling (Belfield, 2004) and mode of students' travel to school (Ewing et al, 2004) have employed utility functions. Utility functions are well-known in literature (see Koutsoyiannis, 1979; and Varian, 2003). Mancebon and Muniz (2008) compared the efficiency of a set of Spanish public and private high schools using data envelopment analysis (DEA) and also identified the school inputs.

In this study, the way of making an informed choice of school among three standard private-independent secondary schools is considered. The motivation to use private-independent schools for this study is sequel to the conformity of private-independent schools with the classical paradigm for free market competition and the strong dependence of such schools upon satisfying the desires and expectations of parents. More so, most parents in the Niger Delta region in Nigeria prefer to enrol their children in private-independent schools as they opined that their children are better served and that everyday instruction is ensured irrespective of the price differential among public, private-missionary and private-independent offering. This study is expected to aid households in making an informed choice of private-independent secondary school for their children, particularly those living in educationally less developed areas (ELDAs).

\section{THE PROBLEM}

In ELDAs, the existing schools are substandard and the routes to schools in the cities are in deplorable state. The problem of the household is enrolling the child in a school located outside the walkable neighbourhood of his residential area (usually in the cities), and ensuring that the child takes the most convenient travelling mode, say mode of type $k$, so as to arrive at school as early as possible. We now consider the school choice problem of a household $H$ living in an $X Y$ community in the Niger Delta region in Nigeria who is willing to enrol his child in basic 7 (formerly referred to as J.S.S. 1) in a standard private-independent secondary school far-off from his residence. Three of such private-independent schools, denoted as Sch 1, Sch 2, and Sch 3, are being considered by the household (see figure 1). In each of these schools the number of teaching staff is exactly equal to the number of subjects taught at that level.

The household considered here wishes to enrol his child in a private-independent secondary school based on the available human and physical resources in the school. These include, in descending order of importance as perceived by the household, the following: qualified 
teaching staff, laboratory, health centre, hostel, computers and sports. The household budgets the sum of one hundred and fifteen thousand naira $(\$ 115,000)$ for a session for the child's education. A survey of the three standard private-independent secondary schools reveals the following attributes and statistics for basic 7 for the academic year as presented in Table I.

A river separates the household from the nearest motor park (denoted as node 1) where the child can board taxi, bus or motor bike. Speed boats are available for transporting people and their goods across the river at a cost of $\$ 150$. The allowable speed limit of the boat is $80 \mathrm{~km} / \mathrm{h}$. There are eight other nodes linked to node 1. Some of the links are in deplorable state; for this reason, only motor bikes ply such routes. Each of the three schools is located at node 6, node 7 and node 8. The schematic representation of the network (without the winding routes), mode of transportation and its associated costs (in Naira) enclosed in parenthesis is given in figure 1.

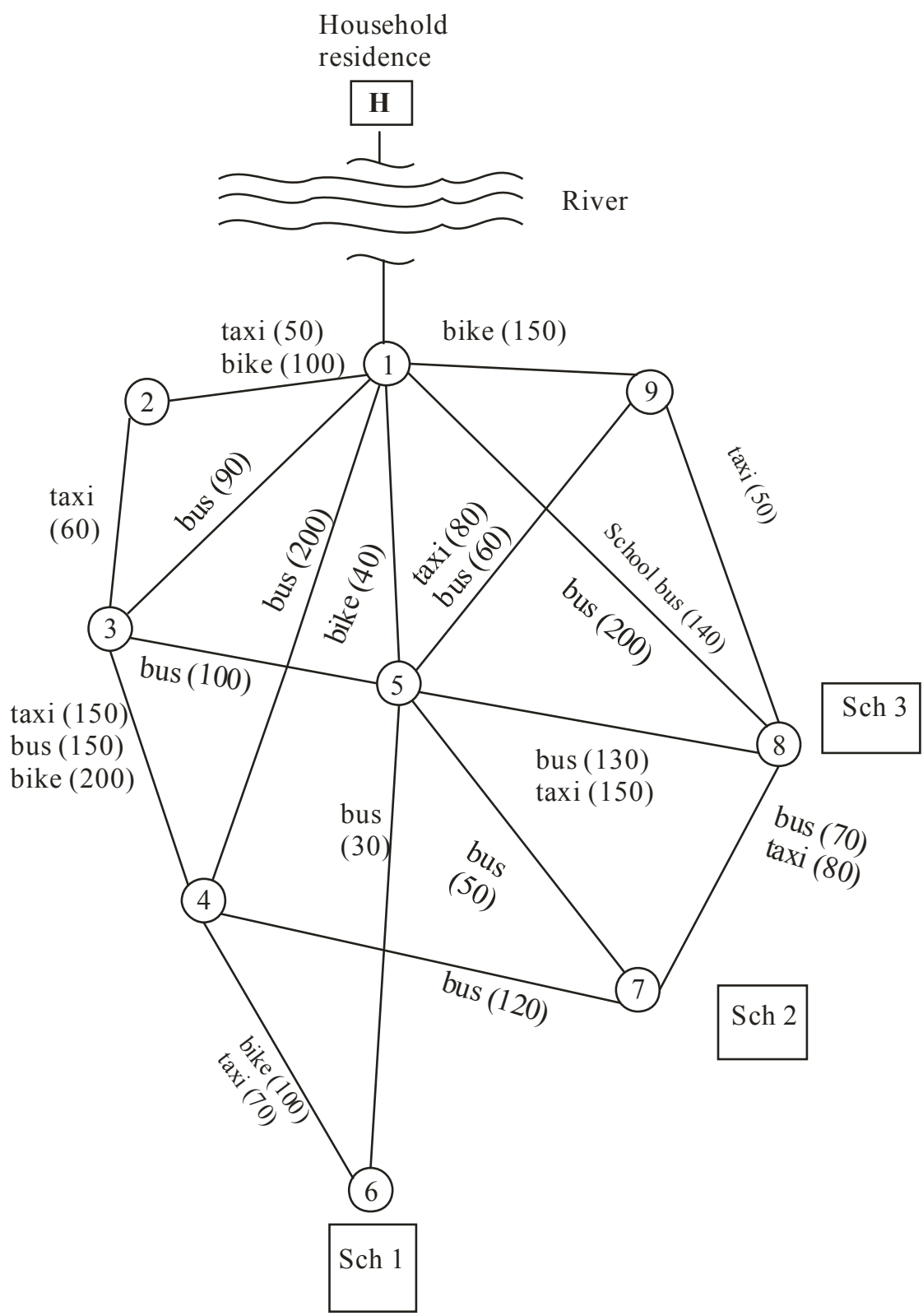

Figure 1: Schematic representation of the transport network and school locations. 
Table I: School attributes and vital statistics

\begin{tabular}{|c|c|c|c|c|c|c|c|c|c|c|}
\hline \multirow{2}{*}{ ס } & \multirow{2}{*}{ \& } & \multicolumn{3}{|c|}{ 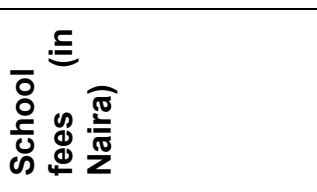 } & \multicolumn{3}{|c|}{ 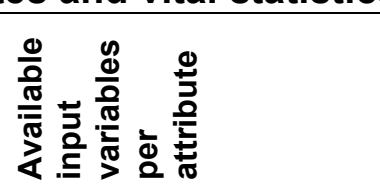 } & \multicolumn{3}{|c|}{$\begin{array}{l}\text { Maximum student size } \\
\text { and distribution for } \\
\text { each attribute }\end{array}$} \\
\hline & & $f_{i 1}$ & $f_{i 2}$ & $f_{i 3}$ & Sch 1 & Sch 2 & Sch 3 & Sch 1 & Sch 2 & Sch 3 \\
\hline $\begin{array}{l}1 . \\
\text { Teaching } \\
\text { staff }\end{array}$ & $\begin{array}{l}\text { Tuition and } \\
\text { examination } \\
\text { fees }\end{array}$ & $\begin{array}{l}8 \\
8 \\
8 \\
\dot{\sigma}\end{array}$ & $\begin{array}{l}8 \\
8 \\
\text { Li }\end{array}$ & $\begin{array}{l}8 \\
8 \\
0 \\
\circ\end{array}$ & 12 & 14 & 16 & 40 & 40 & 35 \\
\hline 2. Hostel & $\begin{array}{l}\text { Accommodation } \\
\text { fees and living } \\
\text { cost }\end{array}$ & $\begin{array}{l}8 \\
8 \\
10\end{array}$ & $\begin{array}{l}8 \\
8 \\
8 \\
\dot{+}\end{array}$ & 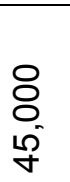 & 2 & 2 & 2 & 80 & 60 & 60 \\
\hline $\begin{array}{l}\text { 3. Health } \\
\text { centre }\end{array}$ & Medical fees & $\begin{array}{l}8 \\
\circ \\
\circ\end{array}$ & $\begin{array}{l}8 \\
8 \\
0\end{array}$ & $\begin{array}{l}8 \\
\text { ○ } \\
0\end{array}$ & 1 & 1 & 1 & 6 & 8 & 6 \\
\hline $\begin{array}{l}4 . \\
\text { Laboratory }\end{array}$ & Laboratory fees & $\begin{array}{l}8 \\
8 \\
\circ\end{array}$ & $\begin{array}{l}8 \\
\text { ¿ } \\
\text { i }\end{array}$ & $\begin{array}{l}8 \\
\varnothing \\
\infty\end{array}$ & 1 & 1 & 1 & 20 & 16 & 20 \\
\hline $\begin{array}{l}5 . \\
\text { Computer } \\
\text { utilization }\end{array}$ & Utility charge & $\begin{array}{l}\circ \\
\circ \\
\circ\end{array}$ & $\begin{array}{l}8 \\
\circ \\
\circ \\
\text { Li }\end{array}$ & $\begin{array}{l}\circ \\
\text { i } \\
\text { m }\end{array}$ & 6 & 8 & 4 & 20 & 16 & 16 \\
\hline 6. Sports & $\begin{array}{l}\text { Common } \\
\text { services charge }\end{array}$ & $\begin{array}{l}8 \\
\text { ণ } \\
\text { i }\end{array}$ & $\begin{array}{l}8 \\
\text { 오 } \\
\text { in }\end{array}$ & ○ & 3 & 4 & 2 & 22 & 22 & 22 \\
\hline
\end{tabular}

$F_{1}=96,000 \quad F_{2}=112,500 \quad F_{3}=114,000$ (all in Naira).

For the safety of commuters and pedestrians, buses, cars and bike often do not exceed $50 \mathrm{~km} / \mathrm{h}$, $60 \mathrm{~km} / \mathrm{h}$ and $40 \mathrm{~km} / \mathrm{h}$, respectively. The household prefers that the child takes a taxicab (or taxi in a shorter form) to school regardless of the opportunity cost of transportation. The household, therefore, is in a quagmire of not only choosing a secondary school from the three standard private-independent secondary schools but also to determine the number of trips to be made using taxi for the child's trip to school.

\section{MODELLING THE SCHOOL CHOICE PROBLEM}

Since the household seeks a standard private-independent school for the child, we first of all define what we mean here by standard schools as schools where the inputs per capita exceed the minimum specification for accreditation. Although we do not have exact information on the accreditation guide by the Ministry of Education in the state, we assume here that the ministry accredits schools if such schools have adequate qualified teaching staff, spacious classroom for at most 40 students per class, standard laboratory equipped for at least practical in the natural and applied science subjects, health centre and computer laboratory. The school choice model in Belfield (2004) cannot be applied to the household school choice problem because the choice of school is not on school ownership types. We do not employ the method of Mancebon and Muniz (2008) because the household is not comparing the programme efficiency of the set of privateindependent schools. We therefore modify the Stone's utility function by adding the number of trips by travelling modes and its corresponding parameters. By this modification, we develop a model 
for a household who is willing to enrol his child in a school located outside his walkable neighbourhood which best satisfies his budget constraint with emphasis on the most preferred travelling mode.

\subsection{Notations and definitions}

In modelling the household school choice problem, we use the following notations.

$a_{i}$ denotes the rank of input variable $i$ according to its preference by the household.

$n$ is the maximum number of school input variables under consideration.

$\gamma_{H}$ is amount to be spent on the child's education for a session.

$f_{i j}$ is the fee charged (per student) for a session for input variable $i$ by school $j$.

$j=1,2, \cdots, M$ are the schools under consideration.

$x_{i j}$ is the existing input $i$ per capita in school $j$.

$x_{i j}^{*}$ is the household demand per capita for input variable $i$ in school $j$.

$\beta_{i}(\geq 0)$ is the minimum standard requirement per capita for variable $i$ as specified by the Ministry of Education or any other recognised body for accreditation of schools in the state.

$c_{r_{H} s_{j}}^{q}$ is the average cost of transportation per student commuter from the pickup point $r$ near $H$ to the drop-off point $s$, before reaching school $j$, using a mode of type $q, m_{q} \in Q=\bigcup_{q=1}^{p}\left\{m_{q}\right\}$, the set of all transport modes.

$A(r, s) \subset Q=\bigcup_{q=1}^{p}\left\{m_{q}\right\}$ is the set of transport modes plying route $(r, s)$.

$T_{r_{H} s_{j}}^{q^{*}}$ is the minimum cost alternative number of trips for the child from the pickup point $r$ near $H$ to the drop-off point $s$, before reaching school $j$ using mode of type $q$.

${ }^{k} T_{r_{H} s_{j}}^{q}$ is the feasible number of trips with minimum cost from the pickup point $r$ near $H$ to the drop-off point $s$, before reaching school $j$, using mode of type $q, m_{q} \in Q$, with emphasis on using the most preferred travelling mode of type $k$.

$T_{r_{H} s_{j}}^{k^{*}}$ is the Lagrange determined number of trips from the pickup point $r$ near $H$ to the drop-off point $s$, before reaching school $j$, using the most preferred mode $k$, at the household saturation point.

$T_{r_{H} s_{j}}^{k^{* *}}$ is the household expected number of trips from the pickup point $r$ near $H$ to the drop-off point $s$, before reaching school $j$, using the most preferred mode $k$.

$T_{r_{H} s_{j}}^{q^{\prime}}$ is the feasible number of trips with minimum cost from the pickup point $r$ near $H$ to the dropoff point $s$, before reaching school $j$, using mode of type $q^{\prime}, m_{q^{\prime}} \in Q /\left\{m_{k}\right\}$.

$\wp^{q}$ is the proportion of recommended safety speed limit for mode of type $q$.

$\alpha_{i}$ is the relative weight assigned to input variable $i$ according to its preference by the household. $m_{q}(r, s)$ is the trip from node $r$ to node $s$ by mode $m$ of type $q,\{q=1,2,3,4,5\}$, where $m$ stands for commercial engine-powered transport services.

Let $m_{1}$ stands for speed boat, $m_{2}$ for bike, $m_{3}$ for taxi, $m_{4}$ for bus, and $m_{5}$ for school bus of Sch 3 . The most preferred travelling mode is $m_{3}$.

\subsection{The budget constraint}

Since the household has allocated a fixed amount for the child's education, we assume that the household is willing to choose the best private-independent secondary school located outside the walkable neighbourhood of his residence for the child provided the total expenditure on the 
child's education for the session is equal to his budget. We also assume that each mode type returns via the route it took on the outgoing trip (tour). Thus, if the amount to be spent on the child's education for a session is $\gamma_{H}$, then the household budget constraint is:

$$
\left(\begin{array}{l}
\text { total } \cos t \text { of school } \\
\text { input } \text { variables }
\end{array}\right)+\left(\begin{array}{l}
\text { total } \cos t \text { of } \\
\text { transportation }
\end{array}\right)=\gamma_{H} .
$$

Equation (1) can be rewritten as

$\sum_{i=1}^{n} f_{i j} x_{i j}+2 \sum_{q=1}^{p} c_{r_{H} s_{j}}^{q} T_{r_{H} s_{j}}^{q}=\gamma_{H}$

$x_{i j} \geq 0, T_{r_{H} s_{j}}^{q} \geq 0, j=1,2, \ldots, M$.

\subsection{The household utility function}

To construct the household utility function, we take $\left(x_{i j}-\beta_{i}\right)>0 \forall i$, as the schools under consideration are standard schools. Expressing the household utility function for school inputs as analogous to Stone's utility function (see Koutsoyiannis, 1979), we have

$U_{1}^{j}=\sum_{i=1}^{n} \alpha_{i} \log _{e}\left(x_{i j}-\beta_{i}\right),(j=1,2, \cdots, M)$.

To ensure that $\sum_{i=1}^{n} \alpha_{i}=1$ (which is a constraint for the marginal budget shares in the Stone's utility function), we define the relative weight of preferences $\alpha_{i}$ as

$$
\alpha_{i}=\frac{2 a_{i}}{n(n+1)} \text {. }
$$

The ranking of the household's preferences to obtain $a_{i}$ follows from the indifference-curves theory (Koutsoyiannis, 1979). The weights $\alpha_{i}$ assigned to the rank of preferences $a_{i}$ in equation (4) are obtained as follows: recall that the sum of ranks in the linear rank statistic is $\sum_{i=1}^{n} a_{i}=\frac{n(n+1)}{2}$ , see Lindgren, 1993; then divide each rank $a_{i}$ by the sum of ranks to obtain its relative weight $\alpha_{i}$. We also assume that the utility from travelling is given by the number of trips weighted by the proportion of speed limits as

$$
U_{2}^{j}=\sum_{q=1}^{p} \wp^{q} T_{r_{H} s_{j}}^{q},(j=1,2, \cdots, M) .
$$

Assuming that the utility from school inputs and that of travelling are independent, then the household utility function, $U_{H}$, is $U_{H}=U_{1}^{j}+U_{2}^{j}$, which can be rewritten as

$$
U_{H}=\sum_{i=1}^{n} \alpha_{i} \log _{e}\left(x_{i j}-\beta_{i}\right)+\sum_{q=1}^{p} \wp^{q} T_{r_{H} s_{j}}^{q},(j=1,2, \cdots, M)
$$

The implication of the assumption leading to the utility function in equation (6) is that there is no possibility of substitution between the school inputs and the number of trips.

\subsection{Mathematical representation of the problem}

Let $F_{j}$ denote the total fees charged by school $j$. The schools $(j=1,2, \cdots, M)$ considered by the household are those satisfying the relation

$$
F_{j}<\gamma_{H}
$$

If $M=1$, then the household has no alternative school. The school choice problem arises when $M>1$. Since $M>1$ for the problem under consideration, then the household has to identify which of the schools best satisfies his demands per capita. To determine the household choice of school therefore, we need to provide a match between the household $H$ demand per capita and each available school input variable $i$ in school $j$ as well as that of the number of trips from the pickup 
point $r$ near $H$ to the drop-off point $s$, using the most preferred mode $k$ before reaching school $j$. In line with the foregoing, we model the household $H$ school choice problem as:

Maximize

subject to

$$
U_{H}=\sum_{i=1}^{n} \alpha_{i} \ln \left(x_{i j}-\beta_{i}\right)+\sum_{q=1}^{p} \wp^{q} T_{r_{H} s_{j}}^{q}
$$

$$
\begin{aligned}
& \sum_{i=1}^{n} f_{i j} x_{i j}+2 \sum_{q=1}^{p} c_{r_{H} s_{j}}^{q} T_{r_{H} s_{j}}^{q}=\gamma_{H} \\
& x_{i j} \geq 0, T_{r_{H} s_{j}}^{q} \geq 0, j=1,2, \ldots, M .
\end{aligned}
$$

\subsection{Deriving solutions from the model}

In this section, we present the method for choosing the most desirable school for the household via the theoretic solutions from problem (8) and the transport network.

\subsubsection{The algorithm for minimum cost school trips}

The transport network in figure 1 is a graph of the form $G=(V, E)$ where $r, s \in V$, is the set of nodes, including the household residence, and $E$ is the set of routes. For every route $e=(r, s) \in E \subseteq V \times V$, a nonnegative cost per commuter passing through the route $r \rightarrow s$ by a mode of type $q, c[q ; r, s]$, is associated with it. There is only one source, $H$, which is the household residence and several sink nodes, $s_{j}$, which are the school locations. The routines for finding the number of trips with minimum cost and the number of trips with preference for the most preferred travelling mode of type $k$ are as follow.

Step 0: Identify the source, $H$, and the sinks, $s_{j}, j=1,2, \cdots, M$.

Step 1: Consider each node $j^{*}$, directly linked to $H$. Obtain

$c\left[q^{*} ; H, j^{*}\right]=\min _{\forall m_{q}}\left\{c\left[q ; H, j^{*}\right]\right\} \quad$ for each $e=\left(H, j^{*}\right) \in E$,

and for the most preferred travelling mode of type $k$,

(Ties are broken arbitrarily). Set $\zeta=2$.

General step $\zeta$ : Let $\Psi_{j^{*}}$ be a sub-graph of $G$ rooted at node $j^{*}$. Let $e^{(\tau)}=\left(r^{(\tau)}, s^{(\tau)}\right)$,

$\tau=1,2, \ldots, w$, be all possible routes leading to $s_{j}$. Compute

$C\left[r_{H}, s_{j}\right]=c\left[q^{*} ; H, j^{*}\right]+\min _{\forall m_{q}}\left\{\sum_{e \in \Delta} c[q ; r, s]\right\}, \quad$ for each node $j^{*}$

where $C\left[r_{H}, s_{j}\right]$ is the minimum outgoing total cost for the child's trip to school $j$, and $\Delta=\Psi_{j^{*}} \cap\left(\bigcup_{\tau=1}^{w}\left\{e^{(\tau)}\right\}\right)$.

For the most preferred travelling mode of type $k$, compute

$$
C_{k}\left[r_{H}, s_{j}\right]=c_{k}\left[q^{*} ; H, j^{*}\right]+\min _{\forall m_{q}}\left\{\sum_{e \in \Delta} c_{k}[q ; r, s]\right\}, \quad \text { for each node } j^{*}
$$

where

$$
c_{k}[q ; r, s]= \begin{cases}c[k ; r, s] & \text { for } m_{k} \in A(r, s) \\ c\left[q^{\prime} ; r, s\right] & \text { for } m_{k} \notin A(r, s)\end{cases}
$$

If $j=M$, stop. 
The sequence $\left\{\sigma^{(\tau)}\right\}_{\tau=1}^{\eta}, \eta \leq w, \quad \ni s^{(\tau)}=r^{(\tau+1)}, \sigma^{(\tau)} \in \bigcup_{\tau=1}^{w}\left\{e^{(\tau)}\right\}$, which yields the minimum outgoing total cost $C\left[r_{H}, s_{j}\right]$, is the path with the minimum cost to school $j$. The number of trips with minimum cost to school $j$ is therefore: $T_{r_{H} s_{j}}^{q^{*}}=\eta$.

Number of trips using the most preferred travelling mode of type $k$ to school $j$ is:

$$
{ }^{k} T_{r_{H} s_{j}}^{k}={ }^{k} T_{r_{H} s_{j}}^{q^{*}}-{ }^{k} T_{r_{H} s_{j}}^{q^{\prime}}, \quad m_{q^{\prime}} \in Q /\left\{m_{k}\right\},
$$

where ${ }^{k} T_{r_{H} s_{j}}^{q^{*}}$ is the number of trips which yields the outgoing total cost $C_{k}\left\lfloor r_{H}, s_{j}\right\rfloor$. The average cost of transportation per student commuter from the pickup point $r$ near $H$ to the drop-off point $s$, before reaching school $j$, with emphasis on using mode of type $k$ is $c_{r_{H} s_{j}}^{k^{*}}$.

\subsubsection{The Lagrangian approach}

The school input variables and number of trips to be made by the most preferred travelling mode of type $k$ maximising problem (8) can be obtained using the Lagrangian method. The Lagrangian function is

$$
L=\sum_{i=1}^{n} \alpha_{i} \log _{e}\left(x_{i j}-\beta_{i}\right)+\sum_{q=1}^{p} \wp^{q} T_{r_{H} s_{j}}^{q}+\lambda\left[\gamma_{H}-\sum_{i=1}^{n} f_{i j} x_{i j}-2 \sum_{q=1}^{p} c_{r_{H} s_{j}}^{q} T_{r_{H} s_{j}}^{q}\right],
$$

where $\lambda$ is the Lagrange multiplier (Kamien and Schwartz, 1992). Differentiating $L$ with respect to $x_{i j}, T_{r_{H} s_{j}}^{k}$, and $\lambda$, and solving the resulting equations after setting the derivatives to zero, we obtain $x_{i j}^{*}=\frac{2 \alpha_{i} c_{r s_{j}}^{k^{*}}}{f_{i j} \wp^{k}}+\beta_{i},(j=1,2, \cdots, M)$,

and $T_{r_{H} s_{j}}^{k^{*}}=\frac{1}{2 c_{r_{H} s_{j}}^{k^{*}}}\left\{\gamma_{H}-2\left(\frac{c_{r_{H} s_{j}}^{k^{*}}}{\wp^{k}}+\frac{1}{2} \sum_{i=1}^{n} f_{i j} \beta_{i}+\sum_{\substack{q=1 \\ q \neq k}}^{p} c_{r_{H} s_{j}}^{q^{\prime}} T_{r_{H} s_{j}}^{q^{\prime}}\right)\right\},(j=1,2, \cdots, M)$.

Equation (13) is the household demand per capita for input variable $i$ in school $j$, while equation (14) is the Lagrange determined number of trips from the pickup point $r$ near $H$ to the drop-off point $s$, to be made by the most preferred mode $k$ at the household saturation point for the child's trip to school $j$. Since $x_{i j}^{*}$ is expressed as input per capita, it takes fractional values. However, if the child is a day student, then $c_{r_{H} s_{j}}^{q}$ is replaced by $\rho c_{r_{H} s_{j}}^{q}$, where $\rho$ is the number of school days (excluding holidays) in a session.

\subsubsection{Verisimilitude of decision variables}

We match the household $H$ demand per capita for each of the school input variable $i$ and the expected number of trips from the pickup point $r$ near $H$ to the drop-off point $s$, made by the most preferred mode $k$ before reaching school $j$ as:

$\min _{j}\left(\Theta_{j}^{\prime} \Theta_{j}\right)$,

where $\Theta_{j}=\left(\theta_{1 j}, \theta_{2 j}, \cdots, \theta_{n j}, \theta_{(k) j}\right)$ is an $(n+1)$-dimensional row vector, $\theta_{i j}$ is given as

$$
\theta_{i j}=\frac{1}{\sqrt{n+1}}\left|\frac{x_{i j}-x_{i j}^{*}}{x_{i j}^{*}}\right|
$$

and $\theta_{(k) j}$ is $\theta_{(k) j}=\frac{1}{\sqrt{n+1}}\left|\frac{T_{r_{H} s_{j}}^{k}-T_{r_{H} s_{j}}^{k^{* *}}}{T_{r_{H} s_{j}}^{k^{*}}}\right|$.

(The scaling factor $\sqrt{n+1}$ is employed so as to account for the number of entries in vector $\Theta_{j}$ ). $T_{r_{H} s_{j}}^{k^{* *}}$ is obtained as $T_{r_{H} s_{j}}^{k^{* *}}=\left[z_{j}\right]$, 
where $z_{j}=\min \left(T_{r_{H} s_{j}}^{k^{*}},{ }^{k} T_{r_{H} s_{j}}^{k}\right)$, and $[z]$ is the largest integer $\leq z$. This is done so as to avoid situations where $T_{r_{H} s_{j}}^{k^{*}}>^{k} T_{r_{H} s_{j}}^{k}$ and the possibility of having fractional values of $T_{r_{H} s_{j}}^{k^{*}} \cdot\left(\Theta^{\prime}{ }_{j} \Theta_{j}\right)$ measures the extent to which school $j$ satisfies the household demands. If $\left(\Theta^{\prime}{ }_{j} \Theta_{j}\right) \rightarrow 0$, then school $j$ is a perfect school choice for the household; otherwise the school $j$ is the least desirable school for the household. Hence, the best school choice for the household among all potentially competitive schools is as given by the expression: $\min _{j}\left(\Theta_{j}^{\prime} \Theta_{j}\right)$. We obtain the household $H$ most desirable school in the next session.

\section{RESULTS AND DISCUSSION}

We implement the algorithm in sub-section 3.5.1 in MATLAB. The MATLAB package is chosen because it can easily be used to compute vectors and matrices resulting from the algorithm in sub-section 3.5.1. Inputs of the MATLAB program for each iterative step for Sch 1 are given in the appendix. Thus, we obtain the number of trips and its associated cost(s) to $S c h 1$ as: $C\left[r_{H}, s_{1}\right]=\mathrm{A} 220$ and $T_{r_{H} s_{1}}^{q^{*}}=3, \quad\left\{q^{*}=1,2,4\right\}$; the trip-mode pattern is: $m_{1}(H, 1) \rightarrow m_{2}(1,5) \rightarrow m_{4}(5,6)$. Number of trips using the most preferred travelling mode (taxi) to $S c h 1$ is: ${ }^{3} T_{r_{H} s_{j}}^{3}=4,\left\{q^{\prime}=1\right\}$ with

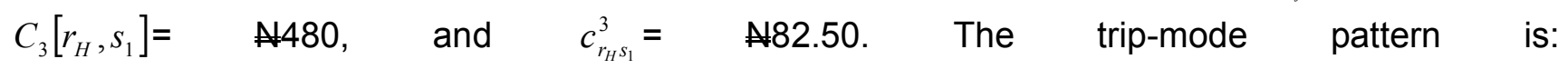
$m_{1}(H, 1) \rightarrow m_{3}(1,2) \rightarrow m_{3}(2,3) \rightarrow m_{3}(3,4) \rightarrow m_{3}(4,6)$.

Number of trips with minimum cost of $C\left[r_{H}, s_{2}\right]=\mathrm{N} 240$ to $S c h 2$ is: $T_{r_{H} s_{2}}^{q^{*}}=3,\left\{q^{*}=1,2,4\right\}$; and the tripmode pattern is: $m_{1}(H, 1) \rightarrow m_{2}(1,5) \rightarrow m_{4}(5,7)$. Number of trips using the most preferred travelling mode (taxi) to $S c h 2$ is: ${ }^{3} T_{r_{H} s_{2}}^{3}=2,\left\{q^{\prime}=1,2\right\}$ with $C_{3}\left[r_{H}, s_{2}\right]=\mathbb{N} 420$ and $c_{r_{H} s_{2}}^{3}=$ N115. The trip-mode pattern is: $m_{1}(H, 1) \rightarrow m_{2}(1,5) \rightarrow m_{3}(5,8) \rightarrow m_{3}(8,7)$.

Number of trips with minimum cost of $C\left[r_{H}, s_{3}\right]=A 290$ to $\operatorname{Sch} 3$ is: $T_{r_{H} s_{3}}^{q^{*}}=2,\left\{q^{*}=1,5\right\}$; and the tripmode pattern is: $m_{1}(H, 1) \rightarrow m_{5}(1,8)$. Number of trips using the most preferred travelling mode (taxi) to $S c h 3$ is: ${ }^{3} T_{r_{H} s_{3}}^{3}=1,\left\{q^{\prime}=1,2\right\}$ with $C_{3}\left[r_{H}, s_{3}\right]=\mathbb{N} 340$ and $c_{r_{H} s_{3}}^{3}=\mathbb{N} 150$. The trip-mode pattern is: $m_{1}(H, 1) \rightarrow m_{2}(1,5) \rightarrow m_{3}(5,8)$.

Using the household preferences for the school inputs in section 2, the ranks for the household school's attributes are: $a_{1}=6, a_{2}=3, a_{3}=4, a_{4}=5, a_{5}=2, a_{6}=1$, for $i=1$ for teaching staff, $i=2$ for hostel, $i=3$ for health centre, $i=4$ for laboratory, $i=5$ for computers, and $i=6$ for sports. From equation (4) we have: $\alpha_{1}=\frac{6}{21}, \alpha_{2}=\frac{3}{21}, \alpha_{3}=\frac{4}{21}, \alpha_{4}=\frac{5}{21}, \alpha_{5}=\frac{2}{21}, \alpha_{6}=\frac{1}{21}$.

Since $\wp^{q}$ is the proportion of recommended safety speed limit for mode of type $q$, from section 3.1, we obtain for speed boat: $\wp^{1}=0.3478$; for bike: $\wp^{2}=0.1739$; for taxi: $\wp^{3}=0.2609$; and for bus: $\wp^{4}=0.2174$.

In section 2, no specific ratio is given for the requirements for school accreditation per se. For this reason, we assume a common per capita divisor of 40 students for each of the specific school input requirements for accreditation as the maximum class size in a standard school is 40 students. School inputs which are not specified among the minimum school input requirements for accreditation take the value zero. Using the assumption in section 3 and equation (13), we obtain the household demands per capita for inputs in Sch 1 as: $x_{11}^{*}=0.0295, x_{21}^{*}=0.0026, x_{31}^{*}=0.0491$, $x_{41}^{*}=0.0401, x_{51}^{*}=0.0401, x_{61}^{*}=0.0151$. Similarly, we obtain the household demands per capita for Sch 2 and Sch 3 respectively as: $x_{12}^{*}=0.0322, \quad x_{22}^{*}=0.0031, \quad x_{32}^{*}=0.0418, \quad x_{42}^{*}=0.0355$, 
$x_{52}^{*}=0.0418, x_{62}^{*}=0.0168, \quad$ and $\quad x_{13}^{*}=0.0316, x_{23}^{*}=0.0037, x_{33}^{*}=0.0587, \quad x_{43}^{*}=0.0592$, $x_{53}^{*}=0.0563, x_{63}^{*}=0.0548$.

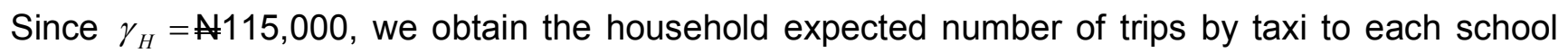
using equation (14) and (17). For Sch 1: $T_{r s_{1}}^{3^{*}}=682.38$ trips. But ${ }^{3} T_{r_{H} s_{1}}^{3}=4$ trips. Therefore $T_{r_{H} s_{1}}^{3^{* *}}=[4]=4$ trips, since $z_{1}=\min (4,682.38)=4$. Similarly, we obtain the household expected number of trips by taxi to $S c h 2$ and $S c h 3$ as: $T_{r_{H} s_{2}}^{3^{* *}}=2$ and $T_{r_{H} s_{3}}^{3^{* *}}=1$, respectively.

To obtain the verisimilitude of decision variables, we first compute the available input per capita in each of the schools. The available inputs per capita in $s c h j$ is computed as follows.

For $i=1$ i.e. teaching staff

$x_{1 j}=\frac{\text { number of teaching staff in sch } j}{(\text { number of subjects taught in sch } j) \times(\max \text { imum allowable class size per subject in sch } j)}$

and for $i=2,3,4,5,6$

$x_{i j}=\frac{\text { available inputs for attribute } i \text { in sch } j}{\text { max imun student size for attribute iin sch } j}$

Using equation (15) and equation (16), we have the following results. For Sch 1 :

$q_{11}=0.0578, q_{21}=3.2822, q_{31}=0.9054, q_{41}=0.0938, q_{51}=2.4526, q_{61}=3.0454, q_{(3) 1}=0.3780$. Thus

vector $\Theta_{1}$ is $\Theta_{1}=(0.0578,3.2822,0.9054,0.0938,2.4526,3.0454,0.3780)$, and $\Theta_{1}^{\prime} \Theta_{1}=27.0369$. Similarly, we obtain for Sch 2 and Sch 3 respectively as: $\Theta_{2}^{\prime} \Theta_{2}=45.30$ and $\Theta_{3}^{\prime} \Theta_{3}=11.47$. The most desirable school for household $H$ is determined by: $\min _{j=1,2,3}\left(\Theta_{j}^{\prime} \Theta_{j}\right)=\Theta_{3}^{\prime} \Theta_{3}=11.47$, and the order of desirability is

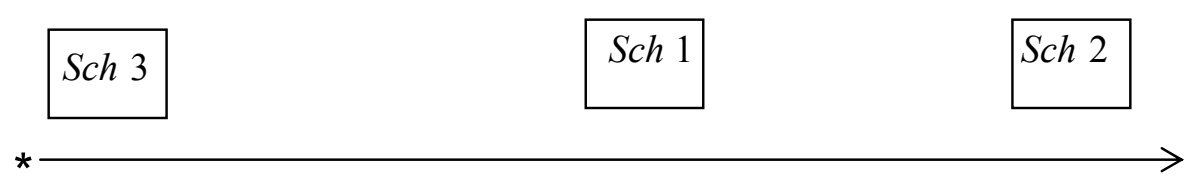

Increasing magnitude of $\Theta_{j}^{\prime} \Theta_{j}$

* - most desirable $\quad \square$ - least desirable

Figure 2: Order of desirability.

The result above implies that household $H$ should enrol his child in $S c h 3$. The decision to do this is not motivated by the provision of school bus by $S c h 3$, as the household prefers that the child takes taxi to school, or because the trip using taxi to Sch 3 is the cheapest relative to that of the other schools, as the household has sufficient funds; rather it is based on the extent to which each of the three schools is able to meet the household taste and preferences. Enrolling the child in Sch 3, the household will incur a total cost of $\$ 114,640$, and the shortfall from $\gamma_{H}$ is the amount to be given to the child as pocket money, which is: pocket money $=\gamma_{H}-\$ 114,680=\$ 320$. The child's mode-trip pattern to Sch 3 is of the form: $m_{1}(H, 1) \rightarrow m_{2}(1,5) \rightarrow m_{3}(5,8)$.

Observe that although $S c h 1$ is the cheapest of the three schools, it is not selected as the most desirable school for the household by the model. By this deduction, we recommend that when a household is faced with the problem of choosing a school among several privateindependent schools, the most desirable school should not be determined by the school charging the lowest fees among them, but by the capacity of the school to meet his demands per capita. This study therefore provides a decision-support tool for the household in making a rational choice of school for the child. 


\section{CONCLUSION}

This work is a development of a normative prototype for school choice decision which enables the household to choose a school located outside his walkable neighbourhood which best satisfies his budget constraint for the school age child in an objective manner. It also employs existing school input variables and most preferable mode of travelling for school choice rather than the ownership-type as in Belfield (2004). Further, it introduces minimum standard of input requirements for schools which directly relate to the child's educational development. Among three private-independent secondary schools considered in this study denoted as Sch $1, S c h 2$, and Sch 3 , Sch 3 was found to be the most desirable school for the household.

\section{REFERENCES}

Belfield, C. R., 2004. Modelling School Choice: A Comparison of Public, Private-Independent, Private-Religious and Home-Schooled Students. Education Policy Analysis Archives, 12(30): Retrieved from http://epaa.asu. edu/epaa/v12n30/.

Ewing, R., Schroeer, W. and Greene, W., 2004. School Location and Student Travel: Analysis of Factors Affecting Mode Choice. Journal of the Transportation Research Board, 1895:55-63.

Kamien, M. I., and Schwartz, N. L., 1992. Dynamic Optimization: The Calculus of Variations and Optimal Control in Economics and Management ( $2^{\text {nd }}$ Ed. $)$. Elsevier, Amsterdam.

Koutsoyiannis, A., 1979. Modern Microeconomics. MacMillan Press Ltd., London.

Lindgren, B. W., 1993. Statistical Theory ( $4^{\text {th }}$ Ed.). Chapman \& Hall, New York.

Mancebon, M. J. and Muniz, M. A., 2008. Private versus Public High Schools in Spain: Disentangling Managerial and Programme Efficiencies. Journal of the Operational Research Society, 59, (7): 892-901.

Varian, H. R., 2003. Intermediate Microeconomics: A Modern Approach (6th Ed). W. W. Norton \& Company, Inc., New York.

\section{APPENDIX}

$\%$ To find the minimum cost trip between nodes.

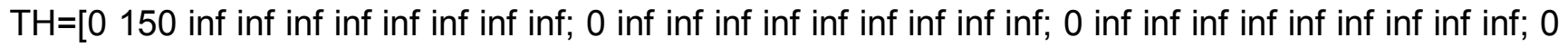
inf inf inf inf inf inf inf inf inf; 0 inf inf inf inf inf inf inf inf inf];

T1=[150 0 inf inf inf inf inf inf inf inf; inf 0100 inf inf 40 inf inf inf 150; inf 050 inf inf inf inf inf inf inf; inf 0 inf 90200 inf inf inf 200 inf; inf 0 inf inf inf inf inf inf 140 inf];

T2=[inf inf 0 inf inf inf inf inf inf inf; inf 1000 inf inf inf inf inf inf inf; inf 50060 inf inf inf inf inf inf; inf inf 0 inf inf inf inf inf inf inf; inf inf 0 inf inf inf inf inf inf inf];

T3=[inf inf inf 0 inf inf inf inf inf inf; inf inf inf 0200 inf inf inf inf inf; inf inf 600150 inf inf inf inf inf; inf 90 inf 0150100 inf inf inf inf; inf inf inf 0 inf inf inf inf inf inf];

T4=[inf inf inf inf 0 inf inf inf inf inf; inf inf inf 2000 inf 100 inf inf inf; inf inf inf 1500 inf 70 inf inf inf; inf 200 inf 1500 inf inf 120 inf inf; inf inf inf inf 0 inf inf inf inf inf];

T5=[inf inf inf inf inf 0 inf inf inf inf; inf 40 inf inf inf 0 inf inf inf inf; inf inf inf inf inf 0 inf inf 150 80; inf inf inf 100 inf 03050130 60; inf inf inf inf inf 0 inf inf inf inf]; 
T6=[inf inf inf inf inf inf 0 inf inf inf; inf inf inf inf 100 inf 0 inf inf inf; inf inf inf inf 70 inf 0 inf inf inf; inf inf inf inf inf 300 inf inf inf; inf inf inf inf inf inf 0 inf inf inf];

T7=[inf inf inf inf inf inf inf 0 inf inf; inf inf inf inf inf inf inf 0 inf inf; inf inf inf inf inf inf inf 080 inf; inf inf inf inf 12050 inf 070 inf; inf inf inf inf inf inf inf 0 inf inf];

T8=[inf inf inf inf inf inf inf inf 0 inf; inf inf inf inf inf inf inf inf 0 inf; inf inf inf inf inf 150 inf 800 50; inf 200 inf inf inf 130 inf 700 inf; inf 140 inf inf inf inf inf inf 0 inf];

T9=[inf inf inf inf inf inf inf inf inf 0; inf 150 inf inf inf inf inf inf inf 0; inf inf inf inf inf 80 inf inf 50 0; inf inf inf inf inf 60 inf inf inf 0; inf inf inf inf inf inf inf inf inf 0];

$[\mathrm{m}, \mathrm{q}]=\min (\mathrm{TH})$, $[\mathrm{m} 1, \mathrm{q} 1]=\min (\mathrm{T} 1)$, $[\mathrm{m} 2, \mathrm{q} 2]=\min (\mathrm{T} 2)$, $[\mathrm{m} 3, \mathrm{q} 3]=\min (\mathrm{T} 3)$, $[\mathrm{m} 4, \mathrm{q} 4]=\min (\mathrm{T} 4)$, $[\mathrm{m} 5, \mathrm{q} 5]=\min (\mathrm{T} 5)$, $[\mathrm{m} 6, \mathrm{q} 6]=\min (\mathrm{T} 6)$, $[\mathrm{m} 7, \mathrm{q} 7]=\min (\mathrm{T} 7)$, $[\mathrm{m} 8, \mathrm{q} 8]=\min (\mathrm{T} 8)$, $[\mathrm{m} 9, \mathrm{q} 9]=\min (\mathrm{T} 9)$,

$\%$ To obtain the total cost of each set of links to school 1 located at $j=6$.

$\mathrm{LHj} 1=[\mathrm{m}(1,2), \mathrm{m} 1(1,3), \mathrm{m} 2(1,4), \mathrm{m} 3(1,5), \mathrm{m} 4(1,7)]$;

$\mathrm{SHj} 1=\operatorname{sum}(\mathrm{LHj} 1)$,

$\mathrm{LHj} 2=[\mathrm{m}(1,2), \mathrm{m} 1(1,4), \mathrm{m} 3(1,5), \mathrm{m} 4(1,7)]$;

$\mathrm{SHj} 2=\operatorname{sum}(\mathrm{LHj} 2)$,

$\mathrm{LHj} 3=[\mathrm{m}(1,2), \mathrm{m} 1(1,5), \mathrm{m} 4(1,7)]$;

$\mathrm{SHj} 3=\operatorname{sum}(\mathrm{LHj} 3)$,

$\mathrm{LHj} 4=[\mathrm{m}(1,2), \mathrm{m} 1(1,6), \mathrm{m} 5(1,7)]$;

$\mathrm{SHj} 4=\operatorname{sum}(\mathrm{LHj} 4)$,

$\mathrm{LHj} 5=[\mathrm{m}(1,2), \mathrm{T} 1(4,9), \mathrm{m} 8(1,8), \mathrm{m} 7(1,6), \mathrm{m} 5(1,7)]$;

$\mathrm{SHj} 5=\operatorname{sum}(\mathrm{LHj} 5)$,

$\mathrm{LHj} 6=[\mathrm{m}(1,2), \mathrm{T} 1(4,9), \mathrm{m} 8(1,6), \mathrm{m} 5(1,7)]$;

$\mathrm{SHj6}=\operatorname{sum}(\mathrm{LHj} 6)$,

$\mathrm{LHj} 7=[\mathrm{m}(1,2), \mathrm{T} 1(4,9), \mathrm{m} 8(1,8), \mathrm{m} 7(1,5), \mathrm{m} 4(1,7)]$;

$\mathrm{SHj} 7=\operatorname{sum}(\mathrm{LHj} 7)$,

$\mathrm{LHj} 8=[\mathrm{m}(1,2), \mathrm{m} 1(1,10), \mathrm{m} 9(1,9), \mathrm{m} 8(1,8), \mathrm{m} 7(1,6), \mathrm{m} 5(1,7)]$;

$\mathrm{SHj} 8=\operatorname{sum}(\mathrm{LHj} 8)$,

$\mathrm{LHj9}=[\mathrm{m}(1,2), \mathrm{m} 1(1,10), \mathrm{m} 9(1,9), \mathrm{m} 8(1,6), \mathrm{m} 5(1,7)]$;

$\mathrm{SHj9}=\operatorname{sum}(\mathrm{LHj} 9)$,

LHj10=[m(1,2),m1(1,10),m9(1,9),m8(1,8),m7(1,5),m4(1,7)];

$\mathrm{SHj} 10=\operatorname{sum}(\mathrm{LHj} 10)$,

LHj11=[m(1,2),m1(1,10),m9(1,6),m5(1,7)];

$\mathrm{SHj} 11=\operatorname{sum}(\mathrm{LHj} 11)$,

$\%$ Minimum cost trip to school 1. 
$\mathrm{SHj}=\min ([\mathrm{SHj} 1, \mathrm{SHj} 2, \mathrm{SHj} 3, \mathrm{SHj} 4, \mathrm{SHj} 5, \mathrm{SHj} 6, \mathrm{SHj} 7, \mathrm{SHj} 8, \mathrm{SHj} 9, \mathrm{SHj} 10, \mathrm{SHj} 11])$, $[p, s]=\operatorname{size}(\mathrm{LHj} 4)$,

$\%$ To find minimum cost trip to school 1 using the most preferred mode.

$m=[0150$ inf inf inf inf inf inf inf inf];

$q=\left[\begin{array}{lllllllllll}1 & 1 & 1 & 1 & 1 & 1 & 1 & 1 & 1 & 1\end{array}\right]$;

$\mathrm{m} 1=[1500509020040$ inf inf 140 150];

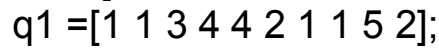

$\mathrm{m} 2=$ [inf 50060 inf inf inf inf inf inf];

q2 = [ $\left.\begin{array}{lllllllllll}1 & 3 & 1 & 3 & 1 & 1 & 1 & 1 & 1 & 1\end{array}\right]$;

m3 =[inf 90600150100 inf inf inf inf];

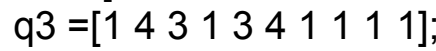

$\mathrm{m} 4=$ =[inf $200 \mathrm{inf} 1500 \mathrm{inf} 70120 \mathrm{inf}$ inf];

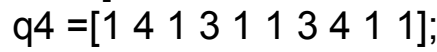

M5 =[inf 40 inf 100 inf 03050150 80];

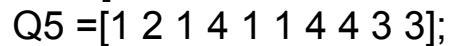

$\mathrm{m} 6=[$ inf inf inf inf 70300 inf inf inf];

q6 $=\left[\begin{array}{lllllllllll}1 & 1 & 1 & 1 & 3 & 4 & 1 & 1 & 1 & 1\end{array}\right]$;

M7 =[inf inf inf inf 12050 inf 080 inf];

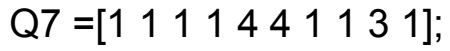

M8 =[inf 140 inf inf inf 150 inf 800 50];

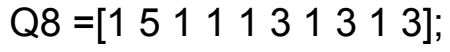

M9 $=[$ inf 150 inf inf inf 80 inf inf 50 0];

$\mathrm{Q} 9=\left[\begin{array}{llllllllll}1 & 2 & 1 & 1 & 1 & 3 & 1 & 1 & 3 & 1\end{array}\right]$;

$\mathrm{IHj} 1=[\mathrm{m}(1,2), \mathrm{m} 1(1,3), \mathrm{m} 2(1,4), \mathrm{m} 3(1,5), \mathrm{m} 4(1,7)]$;

$\mathrm{qc} 1=[\mathrm{q} 1(1,3), \mathrm{q} 2(1,4), \mathrm{q} 3(1,5), \mathrm{q} 4(1,7)]$

$\mathrm{IHj} 2=[\mathrm{m}(1,2), \mathrm{m} 1(1,4), \mathrm{m} 3(1,5), \mathrm{m} 4(1,7)]$;

$\mathrm{qc} 2=[\mathrm{q} 3(1,5), \mathrm{q} 4(1,7)]$;

$\mathrm{IHj} 3=[\mathrm{m}(1,2), \mathrm{m} 1(1,5), \mathrm{m} 4(1,7)]$;

qc3 $=[\mathrm{q} 4(1,7)]$;

$\mathrm{IHj} 5=[\mathrm{m}(1,2), \mathrm{T} 1(4,9), \mathrm{M} 8(1,8), \mathrm{M} 7(1,6), \mathrm{M} 5(1,7)]$;

qc5 $=[Q 8(1,8)]$;

$\mathrm{IHj} 6=[\mathrm{m}(1,2), \mathrm{T} 1(4,9), \mathrm{M} 8(1,6), \mathrm{M} 5(1,7)]$;

$\mathrm{qc6}=[\mathrm{Q} 8(1,6)]$;

$\mathrm{Hj} 7=[\mathrm{m}(1,2), \mathrm{T} 1(4,9), \mathrm{M} 8(1,8), \mathrm{M} 7(1,5), \mathrm{m} 4(1,7)]$;

$\mathrm{qc} 7=[\mathrm{Q} 8(1,8), \mathrm{q} 4(1,7)]$;

$\mathrm{IHj} 8=[\mathrm{m}(1,2), \mathrm{m} 1(1,10), \mathrm{M} 9(1,9), \mathrm{M} 8(1,8), \mathrm{M} 7(1,6), \mathrm{M} 5(1,7)]$;

qc8 $=[Q 9(1,9), Q 8(1,8)]$;

$\mathrm{IHj} 9=[\mathrm{m}(1,2), \mathrm{m} 1(1,10), \mathrm{M} 9(1,9), \mathrm{M} 8(1,6), \mathrm{M} 5(1,7)]$;

qc9 $=[Q 9(1,9), Q 8(1,6)]$;

$\mathrm{IHj} 10=[\mathrm{m}(1,2), \mathrm{m} 1(1,10), \mathrm{M} 9(1,9), \mathrm{M} 8(1,8), \mathrm{M} 7(1,5), \mathrm{m} 4(1,7)]$;

qc10 $=[\mathrm{Q} 9(1,9), \mathrm{Q} 8(1,8)]$;

$\mathrm{IHj} 11=[\mathrm{m}(1,2), \mathrm{m} 1(1,10), \mathrm{M} 9(1,6), \mathrm{M} 5(1,7)]$;

qc11=[Q9 $(1,6)]$;

$\%$ Trip to school 1 with emphasis on using the most preferred mode.

$q c H j=\max ([\operatorname{size}(q c 1), \operatorname{size}(q c 2), \operatorname{size}(q c 3), \operatorname{size}(q c 5), \operatorname{size}(q c 6), \operatorname{size}(q c 7), \operatorname{size}(q c 8), \operatorname{size}(q c 9), \operatorname{size}(q c 1$ $0)$, size(qc11)]),

$\operatorname{sHj} 1=\operatorname{sum}(I H j 1),[r 1, c 1]=\operatorname{size}(q c 1)$

$\%$ Optimum input variables for school 1. 
F1=[40000 350005000100004000 2000]; B=[lo.025 00.0250 .0250 .025 0]; $A=\left[\begin{array}{lllll}6 / 21 & 3 / 21 & 4 / 21\end{array}\right.$ $5 / 21$ 2/21 1/21]; L=[80 4060 50];

$\mathrm{p} 3=\mathrm{L}(1,3) / \operatorname{sum}(\mathrm{L})$,

$\mathrm{c} 3 \mathrm{Hj}=\operatorname{diff}([\mathrm{HHj} 1(1,1), \mathrm{sHj} 1]) / \mathrm{c} 1$,

$\mathrm{y} 1=2^{*} \mathrm{~A}^{*} \mathrm{c} 3 \mathrm{Hj} . /\left(\mathrm{p} 3^{*} \mathrm{~F} 1\right) ; \mathrm{Y} 1=\mathrm{y} 1+\mathrm{B}$,

$\%$ Optimum number of trips to school 1 using the Lagrangian method.

$W=115000 ;[r, c]=\operatorname{size}(q(1,2))$;

$\mathrm{THj}=\left(\mathrm{W}-2^{*}\left(\mathrm{c} 3 \mathrm{Hj} / \mathrm{p} 3+\mathrm{F} 1^{*} \mathrm{~B}^{\prime} / 2+\mathrm{m}(1,2)^{*} \mathrm{c}\right)\right) /\left(2^{*} \mathrm{C} 3 \mathrm{Hj}\right)$,

$\%$ Verissimilitude of decision variables.

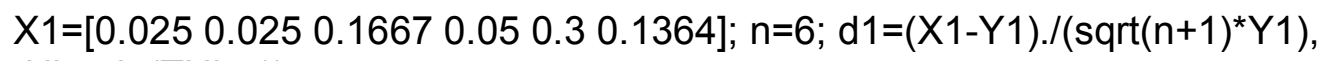

$\mathrm{tHj}=\min (\mathrm{THj}, \mathrm{c} 1)$,

$\mathrm{LHj} 4=[\mathrm{m}(1,2), \mathrm{m} 1(1,6), \mathrm{m} 5(1,7)]$;

$\mathrm{QC1} 1=[] ;[\mathrm{R} 1, \mathrm{C} 1]=\operatorname{size}(\mathrm{QC} 1)$;

$\mathrm{k} 1=(\mathrm{C} 1-\mathrm{tHj}) /\left(\mathrm{sqrt}(\mathrm{n}+1)^{*} \mathrm{tHj}\right), \mathrm{D} 1=[\mathrm{d} 1,[\mathrm{k} 1]], \mathrm{SE} 1=\mathrm{D} 1^{*} \mathrm{D} 1{ }^{\prime}$, 